\title{
Aspectos ecológicos de um trecho de floresta de brejo em Itatinga, SP: florística, fitossociologia e seletividade de espécies
}

\author{
NATÁLIA MACEDO IVANAUSKAS ${ }^{1}$, RICARDO RIBEIRO RODRIGUES ${ }^{2} \mathrm{e}$ \\ ANDRÉ GUSTAVONAVE ${ }^{3}$
}

(recebido em 11/10/95; aceito em 26/12/96)

\begin{abstract}
Ecological aspects of a swamp forest at Itatinga, SP: floristics, phytosociology and species selectivity). On present work, it was studied a swamp forest with 2 ha area, at the EUCATEX Ltda.'s Santa Irene farm, at Itatinga (48 $38^{\prime} 53.2^{\prime \prime W}$ and $23^{\circ} 17^{\prime} 41.6^{\prime \prime S}$ ), São Paulo state. Phytosociological survey was executed through census method in 1 ha of forest remaining, where all individuals with PBH (perimeter at breast height) $\geq 15 \mathrm{~cm}$ were recorded. 1310 individuals were sampled, belonging to 28 families, 34 genera and 39 species of shruby-tree layer. The most important families in IVC were Clusiaceae (53.49), Burseraceae (41.30), Euphorbiaceae (31.42), Podocarpaceae (9.04), Caesalpiniaceae (6.99), Myrsinaceae (6.38), Melastomataceae (5.75), Anacardiaceae (5.70), Arecaceae (4.51) and Styracaceae (4.44). These 10 families accounted for $74.50 \%$ of total IVC. The most important species in IVC were Calophyllum brasiliense (53.49), Protium almecega (41.30), Pera obovata (14.46), Podocarpus sellowii (9.04), Hyeronima alchorneoides (8.68), Copaifera langsdorffii (6.99), Rapanea guianensis (5.72), Tapirira guianensis (5.70), Miconia ligustroides (5.62) e Sebastiania serrata (4.71), wich accounted for $77.84 \%$ of total IVC. The Shannon's diversity index $\left(\mathrm{H}^{\prime}\right)$ was 2.751 nats/individuals. Based on floristic and phytosociological criterious, the species sampled was divided in two groups: a) peculiar species, with the subgroups of exclusive and no exclusive e b) complemental, with the subgroups of dry areas and indifferents.
\end{abstract}

RESUMO - (Aspectos ecológicos de um trecho de floresta de brejo em Itatinga, SP: florística, fitossociologia e seletividade de espécies). No presente trabalho estudou-se um trecho de floresta de brejo localizada na fazenda Santa Irene, de propriedade da EUCATEX Ltda., no município de Itatinga-SP (48 $38^{\prime} 52,2^{\prime \prime W}$ e $23^{\circ} 17^{\prime} 41,6^{\prime \prime}$ 'S), com uma área de 2 ha. O levantamento fitossociológico foi realizado através do método de censo de 1 ha do remanescente florestal, onde foram amostrados todos os indivíduos com PAP (perímetro à altura do peito) $\geq$ a $15 \mathrm{~cm}$. Foram amostrados 1310 indivíduos, pertencentes a 28 famílias, 34 gêneros e 39 espécies do estrato arbustivo-arbóreo. As famílias que apresentaram os maiores valores de IVC foram Clusiaceae $(53,49)$, Burseraceae $(41,30)$, Euphorbiaceae $(31,42)$. Podocarpaceae $(9,04)$, Caesalpiniaceae $(6,99)$, Myrsinaceae $(6,38)$, Melastomataceae $(5,75)$, Anacardiaceae $(5,70)$, Arecaceae $(4,51)$ e Styracaceae $(4,44)$. Estas 10 famílias somaram 74,50\% do IVC total. As espécies de maior destaque em IVC foram Calophyllum brasiliense (53,49), Protium almecega (41,30), Pera obovata $(14,46)$, Podocarpus sellowii $(9,04)$, Hyeronima alchorneoides (8,68), Copaifera langsdorffii (6,99), Rapanea guianensis (5,72), Tapirira guianensis (5,70), Miconia ligustroides $(5,62)$ e Sebastiania serrata $(4,71)$. Tais espécies somadas perfazem $77,84 \%$ do IVC total. O índice de diversidade de Shannon (H') obtido foi de 2,751 nats/indivíduos. Baseado em critérios florísticos e fitossociológicos, as espécies amostradas foram divididas em dois grupos: a) espécies peculiares, com os subgrupos de peculiares exclusivas e não exclusivas e b) complementares, com os subgrupos de áreas secas e indiferentes.

Key words - Phytosociology, swamp forest, ciliar forest, Itatinga

\section{Introdução}

A formação florestal ocorrente nas margens de cursos d'água já recebeu as mais diversas designações, de acordo com as características locais de relevo, solo, declividade, fisionomia ou posição na paisagem, entre outras. Veloso \& Goes Filho (1982) a denominaram de mata aluvional e, quando

1. Instituto de Biologia, Universidade Estadual de Campinas, Caixa Postal 1170, 13081-970 Campinas, SP, Brasil.

2. Escola Superior de Agricultura "Luiz de Queiroz", Universidade de São Paulo, Av. Pádua Dias, 11, Caixa Postal 9, 13418-900 Piracicaba, SP, Brasil.

3. Sociedade para Defesa do Meio Ambiente de Piracicaba (SODEMAP), Caixa Postal 575, 13400-970 Piracicaba, SP, Brasil. o solo aluvional fazia parte de várzeas, foram chamadas de matas aluvionais fluviais (Campos 1912) ou de florestas paludosas (Lindman \& Ferri 1974, Fernandes \& Bezerra 1990). Já Bertoni \& Martins (1987) denominaram-nas floresta de várzea e Troppmair \& Machado (1974) mata de condensação, quando essas ocupavam fundos de vales, apresentando concentração maior de neblina em algum período do ano.

Como essas formações estão distribuídas na forma de pestanas ao longo dos rios (Campos 1912), foram também chamadas de matas de anteparo (Lindman 1906) e de matas ciliares (Sampaio 1938, Hueck 1972, Bezerra dos Santos 1975). Para o estado de São Paulo a consagração do termo mata 
ciliar se deu com Leitão-Filho (1982), definindo-a como floresta latifoliada higrófila, com inundação temporária.

A designação mata ciliar tem sido usada como sinônimo do termo floresta de galeria (Joly 1970, Veloso 1972, Bezerra dos Santos 1975, Goodland 1975). No entanto, o glossário de ecologia (ACIESP 1987) diferencia esses termos baseado na largura da faixa florestada e na fisionomia da vegetação das áreas circundantes. De acordo com esse trabalho, florestas de galeria são formações florestais ao longo de cursos d'água, em regiões onde a vegetação original de interflúvio não é florestal. Para as regiões onde a vegetação original do interflúvio também é florestal, o glossário recomenda o termo floresta ciliar ou floresta de beira d'água. O termo floresta/mata ciliar definido pela ACIESP (1987) tem sido substituído por floresta/mata ripária (Bertoni \& Martins 1987, Catharino 1989, Mantovani 1989, Rodrigues 1992) reservando o termo floresta/mata ciliar usado na legislação atual, para designações mais genéricas, de uso popular já consagrado, considerando o ecótono ciliar e, portanto, todas as variações florísticas e estruturais de formações florestais ocorrentes ao longo de cursos d'água.

As matas de brejo, também denominadas florestas latifoliadas higrófilas com inundação quase permanente (Leitão-Filho 1982) ou apenas matas higrófilas (Toniato \& Leitão Filho 1995), apesar de freqüentemente aparecerem associadas às matas ripárias e de galeria, são florestas que se diferenciam das florestas ciliares por estarem sujeitas à presença d'água no solo em caráter quase permanente. Essa umidade do solo contribui para a seletividade das espécies ocorrentes nesta formação, relacionada à adaptabilidade fisiológica das mesmas para resistir à saturação hídrica. De acordo com Marques (1994) seriam florestas ciliares com características florísticas e edáficas próprias.

Segundo Leitão-Filho (1982), as matas de brejo apresentam um número relativamente menor e muito particular de espécies, geralmente não decíduas, e cujo estrato superior atinge, em média, 10-12 m de altura.

As matas de brejo restringem-se às áreas de várzeas ou planícies de inundação, em terrenos baixos, mais ou menos planos, que se encontram junto às nascentes ou em situações bem definidas nas margens dos rios, lagos ou depressões naturais. Nestes locais ocorrem solos hidromórficos (Orgânicos, Gleissolos, Areias Quartzosas Hidromórficas, Plintossolos e outros), compondo relevo de morretes e canais superficiais de pequena dimensão, representando uma superfície irregular, por onde a água circula com certa orientação.

Os fatores que definem a ocorrência ou de mata de brejo (fisionomia florestal) ou de campo úmido (fisionomia predominantemente herbácea) em solos tipicamente hidromórficos, são ainda pouco conhecidos. No entanto, acredita-se que essa definição é condicionada por fatores relacionados com a drenagem local da água que corre superficialmente, definida pela presença de impedimentos físicos no solo e/ou alteração da topografia original. Nas áreas com residência mais prolongada de água no solo, onde esta permanece quase estagnada, desenvolver-se-iam formações vegetais herbáceas; nas áreas onde a água tem uma movimentação bem definida em canais superficiais, desenvolver-se-iam formações florestais.

Pelo fato de predominarem sobre solos hidromórficos, as florestas de brejo já se definem numa distribuição naturalmente restrita no Estado de São Paulo. Somada a essa condição naturalmente fragmentada, as áreas ocupadas pelas florestas de brejo sofreram ainda sensível redução em passado recente, devido ao programa de incentivo ao uso agrícola das várzeas e devido à construção de hidrelétricas, esta última provocando a submersão de grande parte desses remanescentes pelos reservatórios de geração de energia.

Segundo Marques (1994) as florestas de brejo estão gradativamente desaparecendo, sem que se conheçam suas características ecológicas e a sua importância na proteção dos mananciais.

Trabalhos realizados em florestas de brejo no Estado de São Paulo são ainda escassos, tendo sido publicado até o momento somente aquele realizado por Torres et al. (1994) em uma área localizada no Centro Experimental do Instituto Agronômico de Campinas.

Visando contribuir para o maior conhecimento deste tipo de formação, são apresentados os resultados de um levantamento fitossociológico realizado em área de floresta de brejo localizada na Fazenda Santa Irene, de propriedade da EUCATEX FLORESTAL Ltda. 


\section{Material e métodos}

A área de estudo está localizada na Fazenda Santa Irene, município de Itatinga, SP, na Depressão Periférica próxima aos limites da Cuesta Basáltica, na microbacia do Paranapanema.

A região abrange arenitos do grupo Pirambóia , onde predominam solos do tipo Latossolo Vermelho Amarelo, Latossolo Vermelho Escuro e Areias Quartzosas, com algumas áreas de solos Hidromórficos.

O clima da região é CWa no sistema de Köeppen, o que indica um clima úmido, quente, com inverno seco. $\mathrm{O}$ mês de menor precipitação é o de julho (20-30 mm) e o mês mais chuvoso o de janeiro (200-225 mm). A temperatura média anual é de $18^{\circ} \mathrm{C}$, com mínima de $10^{\circ} \mathrm{C}$ no mês de julho e máxima de $28^{\circ} \mathrm{C}$ no mês de janeiro.

A fazenda possui área de 3597,81 ha, sendo 1037 ha $(28 \%)$ ocupados por vegetação nativa e o restante com eucalipto e estradas de acesso.

Os tipos vegetacionais existentes na fazenda Santa Irene incluem campo, cerrado, floresta de brejo, floresta ciliares e florestas mesófilas semidecíduas.

A floresta de brejo amostrada neste trabalho ocupa uma área aproximada de 2 ha ( $23^{\circ} 17^{\prime} 41,6^{\prime \prime} \mathrm{S}$ e $\left.48^{\circ} 38^{\prime} 53,2^{\prime \prime} \mathrm{W}\right)$, em relevo plano, ligeiramente inclinado $(6,25 \%$ de declividade), com altitude média de $570 \mathrm{~m}$

O solo onde se localiza esse remanescente foi classificado como Areia Quartzosa Hidromórfica/Glei Húmico (H.L. Figueredo, comunicação pessoal)

O levantamento fitossociológico foi realizado através do método de censo, pelo qual foram amostrados todos os indivíduos com $\mathrm{PAP}$ (perímeto à altura do peito) $\geq \mathrm{a} 15 \mathrm{~cm}$, exceto para os indivíduos que perfilharam acima do solo e abaixo da altura do peito $(0-1,30 \mathrm{~m})$. Para estes, foi adotado o seguinte critério: o indivíduo foi incluído quando pelo menos uma das ramificações obedecia ao critério de inclusão ( $\geq$ a $15 \mathrm{~cm}$ de PAP), sendo então anotado o PAP das demais ramificações, para o cálculo das áreas basais. Para cada indivíduo amostrado foram anotados os valores de PAP, de altura (estimada pela comparação com a vara de coleta), observações especiais (características do tronco, deciduidade, presença de látex, etc.) e coletado material botânico para identificação. O material botânico foi todo processado e identificado no Departamento de Botânica da ESALQ/ USP e depositado no Herbário ESA dessa mesma Instituição.

A coleta de dados foi interrompida quando se obteve uma estabilidade de amostragem demonstrada pela curva do coletor, elaborada sorteando-se blocos de 30 indivíduos relacionados ao número acumulado de espécies obtidas. A área total amostrada foi de 1 ha.

Os dados foram analisados utilizando-se o programa FITOPAC, de autoria de G.J. Shepherd (UNICAMP). Os parâmetros considerados foram os normalmente utilizados em levantamentos fitossociológicos e descritos por Whittaker (1972), Muller-Dombois \& Ellemberg (1974), Rodrigues (1989) e Martins (1993).

Com a finalidade de verificar qual a similaridade florística entre a floresta de brejo estudada e áreas adjacentes de floresta de planalto, foram feitas comparações florísticas entre a mesma e duas áreas de floresta mesófila semidecídua, localizadas na Fazenda Santa Irene. A primeira (mata de planície - M1) localiza-se a 8,6 km da floresta em estudo, sobre Latossolo Vermelho Amarelo (fase arenosa), em uma bacia de sedimentação de relevo suavemente ondulado $(7,5 \%$ de declividade) (Ivanauskas et al., 1995). A outra (mata de encosta M2) localiza-se a 1,4 km, sobre Latossolo Vermelho Escuro, em declive mais acentuado (17\% de declividade) (Nave et. al, 1993).
Para verificar a similaridadde florística existente entre floresta de brejo do estado, também foram realizadas comparacões florísticas entre os resultados deste trabalho e os obtidos por Torres et al. (1994) em floresta de brejo localizada no Centro Experimental do Instituto Agronômico de Campinas. Para todas as comparações foi utilizado o índice de Jaccard.

As espécies amostradas no levantamento fitossociológico foram classificadas em peculiares e complementares, segundo Torres et al. (1992).

Espécies pecualiares seriam aquelas características de floresta de brejo, praticamente não ocorrendo em locais mais secos. No entanto, Torres et al. (1992) citam que algumas destas espécies peculiares poderiam ser encontradas em áreas um pouco mais secas, com encharcamento periódico do solo (florestas ripárias ou de galerias), compartilhando o ambiente com as espécies complementares, mas nesses casos raramente em condição dominante.

Espécies complementares seriam as que poderiam aparecer nos brejos, mas que ocorrem preferencialmente em áreas com encharcamento temporário do solo (florestas ripárias ou de galeria) e até em floresta mais secas, onde não ocorrem encharcamento do solo. Estas espécies complementares estariam no grupo que, segundo Joly \& Silva (1988), ocorrem em todo o gradiente. Seriam aquelas chamadas nesse trabalho de espécies indiferentes ou que possuem mecanismos adaptativos aos diferentes níveis de armazenamento de água do solo, desde o ponto de murcha permanente até à capacidade de campo, e mesmo onde a capacidade de campo é saturada, havendo a presença de água corrente superficial (florestas de brejo).

Utilizando os parâmetros quantitativos da comunidade, juntamente com a florística da floresta de brejo deste e de outros trabalhos realizados nessa formação, reuniram-se as espécies ocorrentes em floresta de brejo em dois grupos, já definidos por Torres et al. (1992), subdivididos em quatro subgrupos, definidos neste trabalho: a) espécies pecualiares, com os subgrupos de peculiares exclusivas e não exclusivas e b) complementares, com os subgrupos de áreas secas e indiferentes. As justificativas e definições de cada subgrupo fazem parte da discussão deste trabalho.

\section{Resultados}

No total foram amostrados 1310 indivíduos (1242 vivos e 68 mortos em pé), pertencentes a 28 famílias, 34 gêneros e 39 espécies do estrato arbustivo-arbóreo (tabela 1). A área total amostrada foi de 1 ha. A curva do coletor (figura 1) mostrou uma tendência à estabilização.

Das 39 espécies, uma está identificada no nível de gênero e duas no nível de família. A não identificação de todos os indivíduos no nível de espécie ocorreu devido à coleta de material apenas vegetativo, de famílias problemáticas taxonomicamente (Myrtaceae e Cyatheaceae), apesar de terem sido consultados especialistas desses grupos.

A floresta é constituída por três estratos: a) um estrato médio correspondente a um dossel irregular 
Tabela 1. Espécies inventariadas em um trecho de floresta de brejo em Itatinga, SP. MB - Posição no IVC (Índice de Valor de Cobertura) das espécies inventariadas na floresta de brejo; M1 - Posição no IVC das espécies inventariadas na mata de planície (Ivanauskas et al. 1995); M2 - Posição no IVC das espécies inventariadas na mata de encosta (Nave et al. 1993). P - peculiar, C - complementar; e exclusiva; ne - não exclusiva, s - de áreas secas, i - indiferentes; ESA - número de registro no Herbario ESA.

\begin{tabular}{|c|c|c|c|c|c|c|c|}
\hline Família & Espécie & Nome vulgar & MB & MI & M2 & & ESA \\
\hline Anacardiaceae & Tapirira guianenses Aubl. & Pau-pombo & 9 & 13 & 3 & $\mathrm{Ci}$ & \\
\hline Aquifoliaceae & Ilex brasiliense Reissek & Caúna da praia & 15 & 52 & & Pne & 17275 \\
\hline Araliaceae & Dendropanax cuneatum Decne \& Planch. & Maria-mole & 17 & 4 & 16 & $\mathrm{Cs}$ & \\
\hline \multirow[t]{2}{*}{ Arecaceae } & Euterpe edulis Mart. & Jussara & 20 & 95 & & Pne & \\
\hline & Syagrus romanzoffiana (Cham.) Glass. & Jerivá & 14 & 25 & 56 & Pne & \\
\hline Asteraceae & Gochnatia polymorpha (Less.) Cabr. & Cambará & 27 & 14 & 13 & $\mathrm{Cs}$ & \\
\hline Bignoniaceae & Tabebuia umbellata (Sond.) Sand. & Ipê-amarelo-do-brejo & 23 & & & $\mathrm{Pe}$ & \\
\hline Burseraceae & Protium almecega March. & Almecegueira & 2 & 5 & 7 & Pne & 16585 \\
\hline Caesalpiniaceae & Copaifera langsdorffii Desf. & Copaíba & 7 & 1 & 43 & $\mathrm{Ci}$ & \\
\hline Cecropiaceae & Cecropia pachystachya Trècul. & Embaúba & 16 & & 70 & Pne & \\
\hline Clethraceae & Clethra scabra Pers. & & 36 & 34 & 81 & Pne & \\
\hline Clusiaceae & Calophyllum brasiliense Camb. & Guanandi & 1 & & 51 & Pne & 16586 \\
\hline Cyatheaceae & Cyathea $s p$ & & 21 & 31 & & Pne & \\
\hline \multirow[t]{4}{*}{ Euphorbiaceae } & Alchornea triplinervia (Spr.) Muell. Arg. & Tapiá & 13 & 37 & & Pne & 17271 \\
\hline & Hyeronima alchorneoides Fr. All. & Licurana & 6 & 62 & 50 & Pne & \\
\hline & Pera obovata Baill. & Pau-de-sapateiro & 3 & 9 & 14 & Pne & \\
\hline & Sebastiania serrata (Baill) Miuell. Arg. & Branquilho & 11 & & & $\mathrm{Pe}$ & \\
\hline Flacourtiaceae & Casearia decandra Jacq. & Pitumba & 33 & 17 & 47 & $\mathrm{Ci}$ & \\
\hline \multirow[t]{2}{*}{ Lauraceae } & Aniba firmula Mez. & Canela-sassafrás & 37 & & & $\mathrm{Pe}$ & \\
\hline & Ocotea beaulahiae Baitello & & 40 & & & $\mathrm{Pe}$ & \\
\hline Magnoliaceae & Talauma ovata St. Hill & Pinha-do-brejo & 22 & & & $\mathrm{Pe}$ & \\
\hline \multirow[t]{2}{*}{ Melastomataceae } & Miconia ligustroides (DC.) Naud. & & 10 & & 17 & Pne & 16587 \\
\hline & Miconia chamissois Naud. & & 35 & & & $\mathrm{Pe}$ & 16596 \\
\hline Meliaceae & Guarea guidonea (L.) Sleum. & Marinheiro, & 32 & & 72 & Pne & 16595 \\
\hline Mimosaceae & Inga affinis $\mathrm{DC}$. & Ingá & 19 & & 61 & Pne & \\
\hline Moraceae & Brosimum gaudichaudii Trécul & Mamica-de-cadela & 24 & & & $\mathrm{C}$ & \\
\hline \multirow[t]{2}{*}{ Myrsinaceae } & Rapanea guianensis Aubl. & Capororoca & 8 & & 62 & Pne & 16594 \\
\hline & Rapanea umbellata (Mart.) Mez. & Capororoca-branca & 26 & 8 & 5 & Cs & 16604 \\
\hline \multirow[t]{5}{*}{ Myrtaceae } & Eugenia florida DC. & Guamirim & 18 & & 89 & Pne & 15498 \\
\hline & Eugenia af. speciosa Camb. & Laranjinha-do-mato & 29 & & & $\mathrm{Pe}$ & \\
\hline & Myrcia rostrata $\mathrm{DC}$ & Lanceira & 30 & 42 & 37 & $\mathrm{Ci}$ & \\
\hline & Myrtaceae 1 & & 39 & 90 & & Pne & \\
\hline & Myrtaceae 2 & & 28 & & & $\mathrm{Pe}$ & \\
\hline Ochnaceae & Ouratea semiserrata (Mart e Nees) Engl. & & 38 & & & $\mathrm{C}$ & \\
\hline Podocarpaceae & Podocarpus sellowii Klotzch ex Endl. & Pinheiro-bravo & 5 & 57 & & Pne & \\
\hline Rosaceae & Prunus sellowii Koehne & Pessegueiro-bravo & 25 & 55 & 41 & Pne & 16626 \\
\hline Rubiaceae & Faramea cyanea Muell. Arg. & & 34 & 21 & & Cs & 16623 \\
\hline Styracaceae & Styrax pohlii A. DC. & Benjoeiro & 12 & 71 & & Pne & 17278 \\
\hline Verbenaceae & Vitex montevidensis Cham. & Tarumã & 31 & & & $\mathrm{Pe}$ & \\
\hline
\end{tabular}

variando entre $8-13 \mathrm{~m}$ de altura, b) um estrato emergente definido pela presença de algumas árvores emergentes de até $18 \mathrm{~m}$ de altura e c) um estrato inferior, correspondendo ao sub-dossel e sub-bosque, de difícil separação nesse tipo de formação.

A cobertura herbácea é praticamente inexistente, restringindo-se a poucos indivíduos de pteridófitas e das famílias Poaceae e Cyperaceae ocorrentes nos morretes formados entre os canais superficiais do solo irregular, onde a água circula com uma orientação pouco definida. Joly \& Silva (1988) atribuíram essa ausência de estrato herbáceo à elevada saturação hídrica do solo.

O dossel é caracterizado pela presença de Podocarpus sellowii (pinheiro-bravo), Hyeronima 


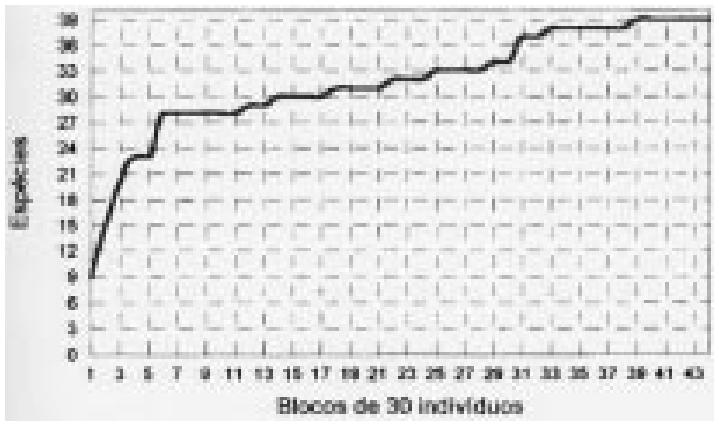

Figura 1. Curva do coletor em um trecho de mata de brejo em Itatinga, SP.

alchorneoides (urucurana), Styrax pohlii (benjoeiro), Alchornea triplinervia (tapiá), como principais.

Tabela 2. Parâmetros fitossociológicos das famílias amostradas em um trecho de floresta de brejo em Itatinga, SP.

\begin{tabular}{lccccc}
\hline Família & $\begin{array}{c}\text { No de } \\
\text { indiví- } \\
\text { duos }\end{array}$ & $\begin{array}{c}\text { No de } \\
\text { espécies }\end{array}$ & $\begin{array}{c}\text { Densi- } \\
\text { dade } \\
\text { Rela- } \\
\text { tiva }\end{array}$ & $\begin{array}{c}\text { Domi- } \\
\text { nância } \\
\text { Rela- } \\
\text { tiva }\end{array}$ & IVC* \\
\hline Clusiaceae & 272 & 1 & 20,76 & 32,73 & 53,49 \\
Burseraceae & 281 & 1 & 21,45 & 19,85 & 41,30 \\
Euphorbiacea & 205 & 4 & 15,65 & 15,77 & 31,42 \\
Morta & 68 & 1 & 5,19 & 6,94 & 12,13 \\
Podocarpaceae & 46 & 1 & 3,51 & 5,52 & 9,04 \\
Caesalpiniaceae & 47 & 1 & 3,59 & 3,40 & 6,99 \\
Myrsinaceae & 57 & 2 & 4,35 & 2,03 & 6,38 \\
Melastomataceae & 45 & 2 & 3,44 & 2,31 & 5,75 \\
Anacardiaceae & 48 & 1 & 3,66 & 2.04 & 5,70 \\
Arecaceae & 36 & 2 & 2,75 & 1,76 & 4,51 \\
Styracaceae & 36 & 1 & 2,75 & 1,69 & 4,44 \\
Myrtaceae & 28 & 5 & 2,14 & 0,90 & 3,03 \\
Aquifoliaceae & 29 & 1 & 2,21 & 0,57 & 2,78 \\
Cecropiaceae & 23 & 1 & 1,76 & 1,00 & 2,76 \\
Araliaceae & 19 & 1 & 1,45 & 0,51 & 1,96 \\
Mimosaceae & 15 & 1 & 1,15 & 0,66 & 1,80 \\
Cyatheaceae & 8 & 1 & 0,61 & 0,76 & 1,37 \\
Magnoliaceae & 9 & 1 & 0,69 & 0,39 & 1,08 \\
Bignoniaceae & 8 & 1 & 0,61 & 0,39 & 1,00 \\
Moraceae & 8 & 1 & 0,61 & 0,15 & 0,76 \\
Rosaceae & 8 & 1 & 0,61 & 0,11 & 0,72 \\
Asteraceae & 3 & 1 & 0,23 & 0,20 & 0,43 \\
Verbenaceae & 1 & 1 & 0,08 & 0,14 & 0,22 \\
Meliaceae & 2 & 1 & 0,15 & 0,04 & 0,20 \\
Lauraceae & 2 & 2 & 0,15 & 0,04 & 0,19 \\
Flacourtiaceae & 2 & 1 & 0,15 & 0,02 & 0,18 \\
Rubiaceae & 2 & 1 & 0,15 & 0,02 & 0,17 \\
Clethraceae & 1 & 1 & 0,08 & 0,03 & 0,11 \\
Ochnaceae & 1 & 0,08 & 0,02 & 0,10 \\
\hline IVC & & & & &
\end{tabular}

* IVC = índice de valor de cobertura
Entre as emergentes observa-se a presença de Callophyllum brasiliense (guanandi), Protium almecega (almecegueira), Pera obovata (pau-de-sapateiro) Copaifera langsdorffii (copaíba), como principais.

Nas condições de sub-dossel e sub-bosque encontram-se Rapanea guianensis (pau-pombo), Sebastiania serrata (branquilho), Miconia ligustroides e Ilex brasiliense (caúna-da-praia), sendo que estas quatro espécies são comuns em áreas de borda, enquanto Dendropanax cuneatum (mariamole), Geonoma brevisphata e Euterpe edulis (jussara) são encontradas em maior número no interior da floresta.

De acordo com a figura 2, a família de maior riqueza florística foi Myrtaceae, com cinco espécies, seguida de Euphorbiaceae (quatro espécies), Myrsinaceae (3), Melastomataceae (2), Arecaceae (2) e Lauraceae (2). 78,57\% das famílias (22 famílias) apresentaram apenas uma espécie. Os parâmetros fitossociológicos das famílias amostradas no levantamento estão apresentados na tabela 2 .

De acordo com a figura 3, observa-se que dez das 27 famílias perfizeram $81,91 \%$ do total de indivíduos. As três famílias mais numerosas (Burseraceae, Clusiaceae e Euphorbiaceae) somaram $61,03 \%$ do total de indivíduos amostrados. O destaque de Burseraceae deveu-se a Protium almecega, única espécie desta família ocorrente na área, com 281 indivíduos amostrados, o mesmo ocorrendo com Clusiaceae, com 272 indivíduos de Callophyllum brasiliense. Já a família Euphorbiaceae destacou-se devido aos indivíduos de quatro espécies: Pera obovata (74 indivíduos), Hyeronima alchorneoides (72 indivíduos),

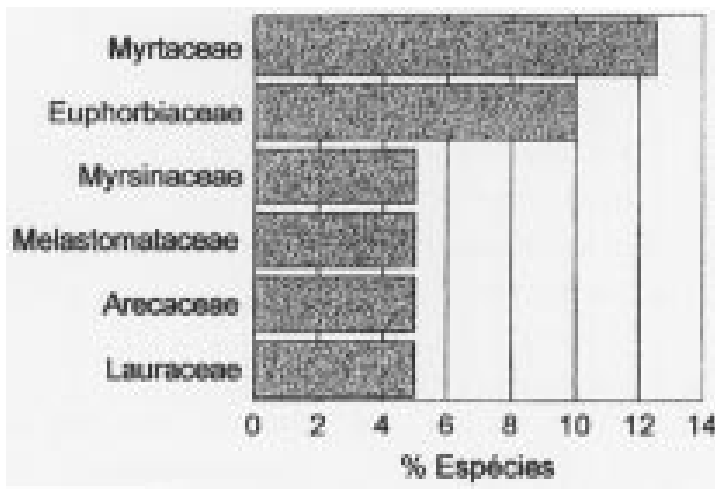

Figura 2. Distribuição percentual das espécies por família. 
Sebastiania serrata (38 indivíduos) e Alchornea triplinervia (21 indivíduos).

O histograma da figura 4, que ordena as famílias por IVC, mostra que dez famílias perfazem $74,50 \%$ do IVC total. A família de maior IVC foi Clusiaceae $(53,49)$ seguida de Burseraceae $(41,30)$ e Euphorbiaceae $(31,42)$, que foram as mesmas que apresentaram o maior número de indivíduos e que juntas somaram $63,10 \%$ do IVC total.

A densidade total do levantamento foi de 1310 indivíduos/ha, com $15 \mathrm{~cm}$ ou mais de PAP (perímetro à altura do peito) e a área basal foi de $18631 \mathrm{~m}^{2} / \mathrm{ha}$.

A tabela 3 apresenta os valores dos parâmetros fitossociológicos das 39 espécies amostradas no levantamento, em ordem decrescente de IVC.

De acordo com a figura 5, dez espécies somam $74,27 \%$ do total de indivíduos amostrados. As espécies mais numerosas foram Protium almecega (281 indivíduos) e Callophyllum brasiliense (272 indivíduos), que juntas somam $42,21 \%$ do número total de indivíduos. A maior diferença $(15,8 \%)$ ocorreu entre Callophyllum brasiliense (2 ${ }^{\mathrm{a}}$ posição) e Pera obovata (3- posição).

Das 39 espécies amostradas, sete apresentaram apenas um indivíduo $(17,95 \%)$, somando $0,53 \%$ do número total de indivíduos.

$\mathrm{Na}$ figura 6 observa-se que dez espécies perfazem $77,84 \%$ do VC total, sendo que Calophyllum brasiliense e Protium almecega apresentam valores de cobertura bem superiores às demais, somando 47,39\% do VC total. Espécies como Callophyllum brasiliense, Pera obovata e Podocarpus sellowii apresentaram destaque no IVC

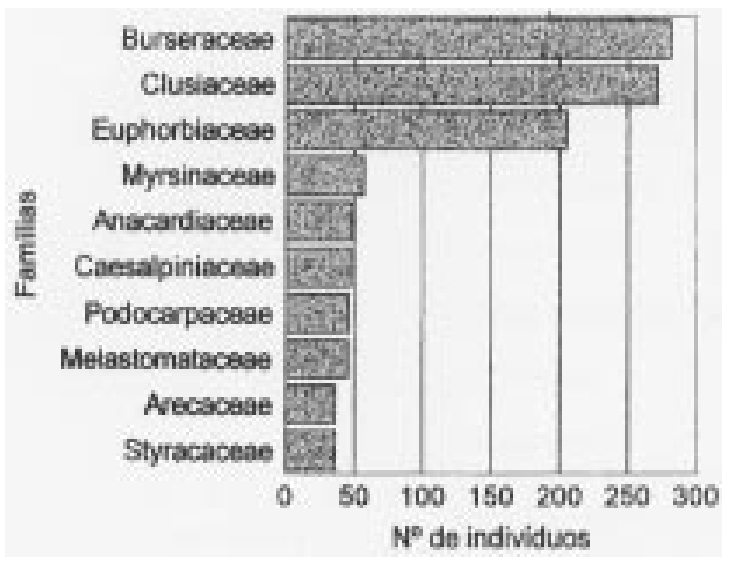

Figura 3. Distribuição do número de indivíduos por família. devido ao porte elevado dos indivíduos amostra-dos, que definem altos valores de dominância. Já Hyeronima alchorneoides e Rapanea guianensis destacaram-se na comunidade pelo elevado número

Tabela 3. Parâmetros fitossociológicos das espécies amostradas em um trecho de floresta de brejo em Itatinga, SP.

\begin{tabular}{|c|c|c|c|c|}
\hline Espécie & $\begin{array}{c}\text { № de } \\
\text { indiví- } \\
\text { duos }\end{array}$ & $\begin{array}{c}\text { Densi- } \\
\text { dade } \\
\text { Rela- } \\
\text { tiva }\end{array}$ & $\begin{array}{c}\text { Domi- } \\
\text { nância } \\
\text { Rela- } \\
\text { tiva }\end{array}$ & IVC* \\
\hline Calophyllum brasiliense & 272 & 20,76 & 32,73 & 53,49 \\
\hline Protium almecega & 281 & 21,45 & 19,85 & 41,30 \\
\hline Pera obovata & 74 & 5,65 & 8,81 & 14,46 \\
\hline morta & 68 & 5,19 & 6,94 & 12,13 \\
\hline Podocarpus selowii & 46 & 3,51 & 5,52 & 9,04 \\
\hline Hyeronima alchorneoides & 72 & 5,50 & 3,19 & 8,68 \\
\hline Copaifera langsdorffii & 47 & 3,59 & 3,40 & 6,99 \\
\hline Rapanea guianensis & 51 & 3,89 & 1,83 & 5,72 \\
\hline Tapirira guianensis & 48 & 3,66 & 2,04 & 5,70 \\
\hline Miconia ligustroides & 44 & 3,36 & 2,26 & 5,62 \\
\hline Sebastiania serrata & 38 & 2,90 & 1,81 & 4,71 \\
\hline Styrax pohlii & 36 & 2,75 & 1,69 & 4,44 \\
\hline Alchornea triplinervia & 21 & 1,60 & 1,96 & 3,56 \\
\hline Syagrus romanzoffiana & 21 & 1,60 & 1,42 & 3,02 \\
\hline Ilexpseudobuxus & 29 & 2,21 & 0,57 & 2,78 \\
\hline Cecropia pachystachya & 23 & 1,76 & 1,00 & 2,76 \\
\hline Dendropanax cuneatum & 19 & 1,45 & 0,51 & 1,96 \\
\hline Eugenia moraviana & 17 & 1,30 & 0,59 & 1,89 \\
\hline Inga affinis & 15 & 1,15 & 0,66 & 1,80 \\
\hline Euterpe edulis & 15 & 1,15 & 0,34 & 1,49 \\
\hline Cyathea $s p$ & 8 & 0,61 & 0,76 & 1,37 \\
\hline Talauma ovata & 9 & 0,69 & 0,39 & 1,08 \\
\hline Tabebuia umbellata & 8 & 0,61 & 0,39 & 1,00 \\
\hline Brosimum gaudichaudii & 8 & 0,61 & 0,15 & 0,76 \\
\hline Prunus sellowii & 8 & 0,61 & 0,11 & 0,72 \\
\hline Rapanea umbellata & 6 & 0,46 & 0,20 & 0,66 \\
\hline Gochnatia polymorpha & 3 & 0,23 & 0,20 & 0,43 \\
\hline Myrtaceae 3 & 3 & 0,23 & 0,18 & 0,41 \\
\hline Eugenia aff. speciosa & 4 & 0,31 & 0,07 & 0,37 \\
\hline Myrcia rostrata & 3 & 0,23 & 0,04 & 0,27 \\
\hline Vitex montevidensis & 1 & 0,08 & 0,14 & 0,22 \\
\hline Guarea guidonea & 2 & 0,15 & 0,04 & 0,20 \\
\hline Casearia decandra & 2 & 0,15 & 0,02 & 0,18 \\
\hline Faramea cyanea & 2 & 0,15 & 0,02 & 0,17 \\
\hline Miconia chamissois & 1 & 0,08 & 0,06 & 0,13 \\
\hline Clethra scabra & 1 & 0,08 & 0,03 & 0,11 \\
\hline Aniba firmula & 1 & 0,08 & 0,03 & 0,10 \\
\hline Ouratea semiserrata & 1 & 0,08 & 0,02 & 0,10 \\
\hline Myrtaceae 1 & 1 & 0,08 & 0,01 & 0,09 \\
\hline Ocotea beaulahine & 1 & 0,08 & 0,01 & 0,09 \\
\hline
\end{tabular}

*IVC = Índice de Valor de Cobertura 
de indivíduos, definidos pelos altos valores de densidade. As demais espécies principais destacaram-se por valores elevados tanto de dominância quanto de densidade.

\section{Discussão}

Segundo Joly \& Silva (1988), as formações ciliares, fora da área efetivamente afetada pela flutuação do nível do lençol freático, tem a sua composição florística fortemente influenciada pelas formações adjacentes.

Rodrigues (1992), ao realizar comparações entre levantamentos realizados em florestas ripárias, verificou grande heterogeneidade florística e estrutural nessas formações, concordando com Joly \& Silva (1988) sobre a influência das formações adjacentes na composição florística de florestas ripárias.

Rodrigues (1992) verificou ainda que essa heterogeneidade se mantém também dentro da mesma formação, sendo definida pela topografia e pelas características do solo e do curso d'água (calha, volume e velocidade da água). Dependendo dessas características, os efeitos sobre a vegetação, referentes à elevação periódica do nível d'água, e o tempo de duração desse evento, serão distintos e particulares para cada situação específica, dentro de um único contínuo de floresta.

A ocorrência do evento de inundação do solo é condicionada pela elevação do nível do rio na época das cheias e a duração é determinada pela saturação

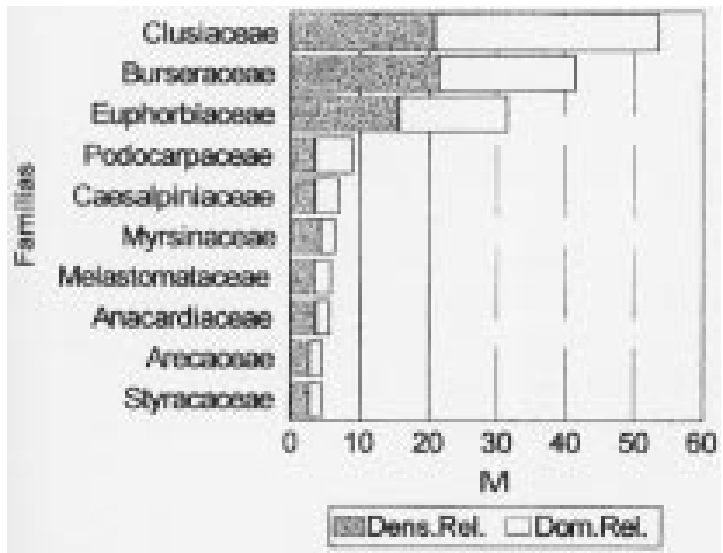

Figura 4. Distribuição do Índice de Cobertura (IVC) por família.

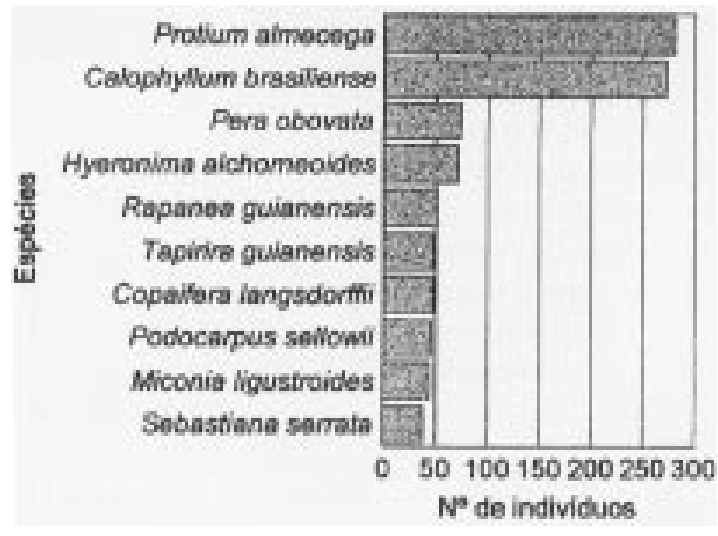

Figura 5. Distribuição do número de indívudos por espécie.

hídrica do solo, que por sua vez está relacionada com a superficialidade do lençol freático (Rodrigues 1992).

Nas florestas de brejo, as condições topográficas são muito semelhantes mesmo entre áreas distintas, já que essa formação está associada a várzeas ou planícies de inundação, em terrenos baixos, mais ou menos planos, que se encontram nas cabeceiras e em situações bem definidas nas margens dos rios, lagos ou depressões naturais. O período de acumulação de água e a duração do encharcamento também são parecidos, já que a presença de água superficial por um período longo também é uma das condições que definem a presença dessa formação.

No entanto, essa provável homogeneidade do ambiente físico não representou uma homogeneidade florística entre florestas de brejo localizadas em regiões distintas, como se mostra adiante.

Segundo Marques (1994), a inundação conduz a uma série de processos físico-químicos e biológicos que influenciam na qualidade do solo como meio para o desenvolvimento das plantas. Ponnamperuma (1984) relatou detalhadamente as modificações que ocorrem no solo durante o alagamento. A mais importante é a diminuição da troca gasosa entre o solo e o ar, causada pela baixa difusão do oxigênio na água. Com isso, o oxigênio é rapidamente consumido e surgem gases como nitrogênio, gás carbônico, hidrogênio e amônia, além de vários outros compostos que podem atingir níveis tóxicos para as plantas. Nessas condições, tanto a germinação das sementes quanto o desenvolvimento das plantas podem ser comprometidos, dependendo 


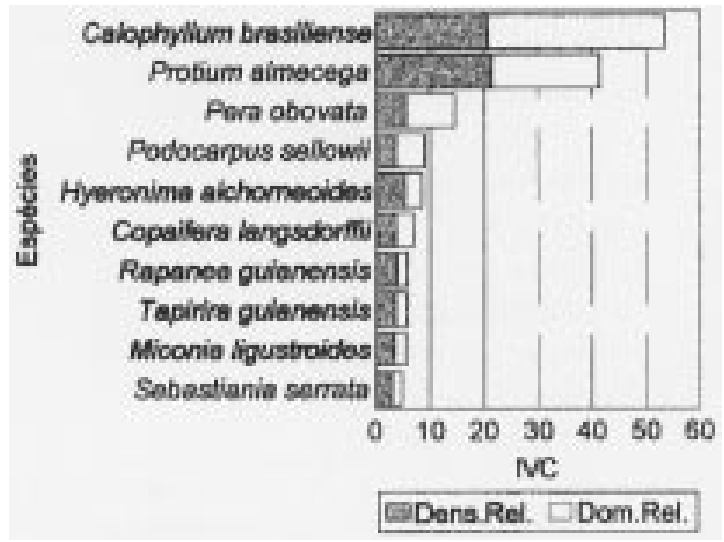

Figura 6. Distribuição do índice de Valor de Cobertura (IVC) por espécie.

da espécie em questão e da duração do período de inundação (Kozlowski 1984).

Relativamente poucas espécies arbóreas tropicais desenvolveram mecanismos adaptativos que permitam a sua sobrevivência em condições anaeróbicas (Joly et al. 1988). No Brasil, os trabalhos de Medri \& Correa (1985), Sena Gomes \& Kozlowski (1988), Lieberg (1990), Joly (1982) e Marques $(1990,1994)$ apresentaram adaptações encontradas em diversas espécies vegetais sujeitas ao alagamento.

Deste modo, a saturação hídrica do solo seria o principal fator atuando na seleção natural das espécies, e estas apresentariam diferentes comportamentos frente a essa situação. Algumas espécies só ocorrem em ambientes com elevada saturação hídrica, sendo que em um outro extremo, existem espécies que só ocorrem em solos onde a saturação hídrica não ultrapasse a capacidade de campo, ou seja, em solos bem drenados.

Isto é demonstrado por Joly \& Silva (1988), ao apresentar a variação da composição florística de um trecho de floresta ciliar ao longo de um gradiente de declividade. Os autores mostraram a existência de um grupo de espécies que ocorreram exclusivamente nas áreas onde havia água corrente acima da superfície do solo. No outro extremo encontraram um grupo de espécies sobre solo bem drenado. Notaram ainda a existência de um terceiro grupo, o das espécies que ocorrem ao longo de todo o gradiente, sendo que estas espécies ocorrem inclusive em outras formações florestais do Brasil, além das florestas ciliares.
Em relação às florestas de brejo, Torres et al. (1992) dividem as espécies que compõem essa formação em dois grupos: as peculiares e as complementares. De acordo com os autores, as florestas de brejo seriam compostas por espécies características dessa formação florestal (peculiares) e por espécies provenientes de formações adjacentes (complementares), sendo que estas formações adjacentes seriam as florestas ripárias, florestas de galeria ou mesmo florestas de planalto no caso da região de estudo.

Para verificar estas designações, mostrou-se necessário esclarecer algumas questões: a) qual seria a composição florística das florestas de brejo, b) qual a similaridade existente entre fragmentos dentro desse tipo de formação e c) qual a similaridade entre essa formação e áreas adjacentes de outras formações florestais, como florestas ripárias, florestas de galeria e florestas de planalto.

$\mathrm{Na}$ comparação entre as florestas estacionais semideciduais amostradas na fazenda Santa Irene, o índice de Jaccard obtido foi de 43,20\%, indicando similaridade florística, já que duas áreas são consideradas semelhantes quando este índice é maior que $25 \%$. Este resultado era o esperado, já que ambas pertencem à categoria de floresta estacional semidecidual, apenas em proporções distintas na composição do mosaico sucessional.

A floresta de brejo não apresentou similaridade florística em relação às outras duas áreas de florestas de planalto, com índices de 21,78\% de similaridade em relação à floresta localizada na planície e de $16,52 \%$ em relação à floresta de encosta. Essa baixa similaridade nos levaria a afirmar que as espécies que ocorrem em florestas de brejo diferem em grande parte das que ocorrem em florestas de planalto. Ocorre que as florestas de planalto apresentam uma diversidade maior em relação às florestas de brejo, já que nas florestas de brejo existe um fator ambiental altamente seletivo para a ocorrência das espécies (saturação hídrica do solo). Essa diversidade elevada das florestas de planalto influencia o cálculo do índice de Jaccard. Isto porque este índice nada mais é do que uma relação entre as espécies comuns às duas condições, sobre a somatória dessas espécies comuns com as espécies exclusivas de cada condição. Como as florestas de planalto apresentam maior número de espécies, o que eleva o numero das exclusivas, a tendência é 
sempre uma baixa relação, não porque os dois ambientes não possuam espécies comuns, mas sim porque o número de espécies das florestas de planalto é maior, concordando com a maior diversidade dessa área. Assim, em outra comparação, podemos constatar que das 39 espécies que ocorreram na floresta de brejo, 11 (28,2\%) foram exclusivas e as outras 28 espécies $(71,79 \%)$ ocorreram também nas florestas de planalto (tabela 1). Com isto podemos concluir que as florestas de brejo tem a sua florística fortemente influenciada pelas formações adjacentes.

Ao analisarmos a distribuição das espécies amostradas nos três levantamentos realizados na Fazenda Santa Irene, observamos que as 136 espécies amostradas dividiram-se em três grupos, concordando com o demonstrado por Joly \& Silva (1988): a) 11 espécies $(8,09 \%)$ foram exclusivas de áreas brejosas; b) 97 espécies $(71,32 \%)$ foram exclusivas de áreas secas e c) 28 espécies $(20,59 \%)$ ocorreram ao longo de todo o gradiente. Esses dados reafirmam a idéia do encharcamento do solo como fator restritivo e atuante na diversidade de espécies em uma relação inversamente proporcional: quanto maior o encharcamento de solo, menor a diversidade encontrada.

As espécies peculiares e complementares da floresta de brejo segundo Torres et al. (1992) fariam parte do grupo das 11 espécies exclusivas de áreas brejosas e do grupo das 28 espécies que ocorreram ao longo de todo o gradiente de umidade. Como os mesmos autores ressaltam em seu trabalho que algumas espécies peculiares de floresta de brejo poderiam ser encontradas em áreas um pouco mais secas, com encharcamento periódico do solo, compartilhando o ambiente com espécies complementares, foi necessária a utilização de parâmetros estruturais para melhor diferenciação entre esses dois grupos. No caso, utilizou-se o destaque em cobertura (IVC) obtido na floresta de brejo e nas florestas de planalto.

Utilizando os parâmetros quantitativos da comunidade, juntamente com a florística da floresta de brejo deste e de outros trabalhos realizados nessa formação, reuniram-se as espécies ocorrentes em florestas de brejo em dois grupos, já definidos por Torres et al. (1992), subdivididos em quatro subgrupos, definidos neste trabalho: a. espécies peculiares

a.1. exclusivas

a.2. não exclusivas

b. espécies complementares

b.1. de áreas secas

b.2. indiferentes

Espécies peculiares exclusivas foram definidas como aquelas que só ocorrem em florestas sujeitas ao encharcamento quase permanente do solo (florestas de brejo), ou seja, possuem área de ocorrência restrita. Este grupo de espécies pode ou não vir a se destacar na estrutura da comunidade das florestas de brejo, mas esse destaque depende de outros parâmetros, que não propriamente a umidade do solo.

As peculiares não exclusivas seriam aquelas que apresentam destaque na estrutura de florestas, sujeitas ao encharcamento quase permanente do solo (florestas de brejo), mas nunca em destaque em áreas com encharcamento periódico do solo (florestas ripárias ou de galeria) ou em áreas um pouco mais secas (florestas de planalto).

As complementares de áreas secas foram definidas como aquelas espécies que se apresentam em destaque na estrutura de florestas sujeitas ao encharcamento periódico do solo (florestas ripárias ou de galeria) ou em áreas um pouco mais secas (florestas de planalto), mas nunca em destaque em áreas com encharcamento quase permanente do solo (florestas de brejo).

As complementares indiferentes não teriam padrão de destaque em importância na estrutura de florestas de brejo, de florestas ripárias ou de galeria e nem de florestas de planalto, ora destacando-se em uma, ora em outra, mas devido a outros fatores que não o encharcamento do solo.

Portanto, o critério que distingue o subgrupo das espécies peculiares exclusivas dos demais é fundamentalmente o florístico. Já as espécies peculiares não exclusivas, complementares de áreas secas e complementares indiferentes diferenciam-se entre si, além do critério florístico, também pelo critério estrutural.

A figura 7 apresenta um esquema ilustrativo dessa proposta de agrupamento das espécies ocorrentes em florestas de brejo, inclusive representando as características de ocupação dessas formações, em termos de destaque na importância, por esses grupos. 


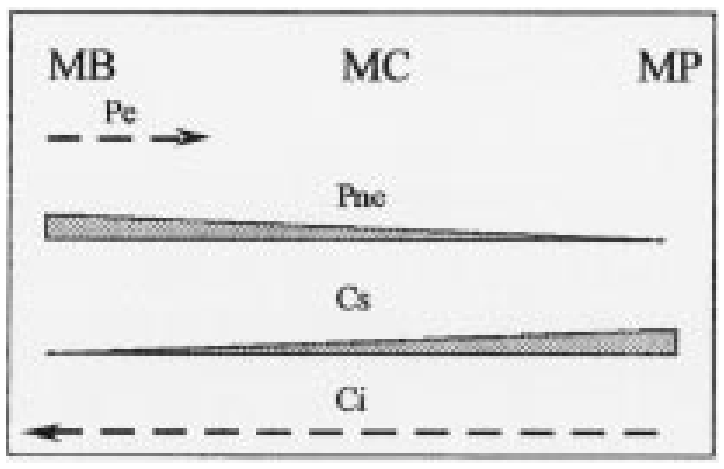

Figura 7. Esquema da divisão dos grupos das espécies ocorrentes em matas de brejo. Pe - peculiares exclusivas; Pne - peculiares não exclusivas; Cs - Complementares de áreas secas; Ci - Complementares indiferentes. $\mathrm{MB}$ - mata de brejo (com encharcamento quase permanente do solo); MC - mata ciliar (com encharcamento periódico do solo); MP - mata de planalto (sem encharcamento do solo). As setas indicam a provável origem das espécies; as linhas inteiras engrossadas, o provável aumento em destaque na importância de cada formação em função do encharcamento do solo; as linhas pontilhadas indicam que o destaque em importância desse grupo de espécies na comunidade pode ou não ocorrer, devido a outros fatores, que não o encharcamento do solo.

Como exemplo de espécies desses grupos, apresentamos aquelas que foram amostradas na floresta de brejo da fazenda Santa Irene, sendo que as proporções de cada subgrupo estão representadas na figura 8.

Como espécies peculiares exclusivas, e que portanto só ocorreram na floresta de brejo (tabela 1), citam-se Aniba firmula, Eugenia af. speciosa, Vitex montevidensis, Miconia chamissois, Ocotea beaulahine, Tabebuia umbellata, Talauma ovata, Sebastiania serrata, Brosimum gaudichaudii, Ouratea semiserrata e uma morfo-espécie da família Myrtaceae (Myrtaceae 2).

As espécies Aniba firmula, Eugenia af. speciosa, Vitex montevidensis, Miconia chamissois, Ocotea beaulahine, Tabebuia umbellata e Talauma ovata são citadas na literatura como típicas de floresta de brejo.

Em relação a Talauma ovata, esta espécie foi citada por Torres et al. (1994) como de ambiente preferencial em floresta de brejo, mas não exclusiva deste, podendo ocorrer em áreas mais secas mas com valores de IVI ou IVC pouco expressivos. Neste trabalho esta espécie ocupou a 22a posição em IVC, mas não foi amostrada nas florestas vizinhas, sendo portanto incluída no grupo das peculiares.
Já Sebastiania serrata é uma espécie citada como presente em outros ambientes, sendo que outras espécies do gênero como Sebastiania brasiliensis, S. edwalliana e S. klotzchiana foram citadas por Torres et al. (1992) como peculiares de floresta de brejo. Segundo especialistas da família Euphorbiaceae, Sebastiania é um gênero bastante complexo, com problemas de identificação taxonômica que justificam a necessidade de uma nova revisão. Após esta revisão, possivelmente terse-á uma melhor definição de quais espécies do gênero possam ser citadas como típicas de floresta de brejo.

As espécies Brosimum gaudichaudii e Ouratea semiserrata, apesar de não amostradas nas florestas adjacentes, não tem as áreas brejosas como ambiente preferencial em outras florestas do estado. Deste modo, a ausência destas espécies nos levantamentos das florestas de planalto adjacentes pode ser atribuída à amostragem, e a sua presença na floresta de brejo como simples eventualidade.

Dessa forma, as espécies citadas como exclusivas, com exceção de Brosimum gaudichaudii e Ouratea semiserrata, e com ressalvas para Sebastiania serrata, podem ser consideradas como peculiares de floresta de brejo, segundo a divisão de Torres et al. (1992).

Como espécies peculiares não exclusivas, destacam-se as espécies que podem vir a ser eventuais em florestas de planalto. Essa eventualidade em áreas secas é confirmada pelo fato de tais espécies aparecerem ou somente na floresta de planície (Ml) ou somente na floresta de encosta (M2), e não em ambos os levantamentos (tabela 1). Tais espécies seriam Calophyllum brasiliense, Podocarpus sellowii, Rapanea guianensis, Miconia ligustroides, Styrax pohlii, Alchornea triplinervia, Ilex pseudobuxus, Cecropia pachystachya, Eugenia florida, Inga affinis, Euterpe edulis, Cyathea sp., Guarea guidonia e Myrtaceae 1.

Torres et. al. (1992) definem Calophyllum brasiliense e Guarea guidonea como espécies peculiares em florestas de brejo. Em relação à Callophyllum brasiliense, segundo Marques (1994) esta é uma espécie extremamente tolerante à saturação hídrica do solo, podendo permanecer nestas condições por um longo período. Esta característica possibilita a sua ocorrência em um gradiente de umidade, que vai desde solos úmidos e 


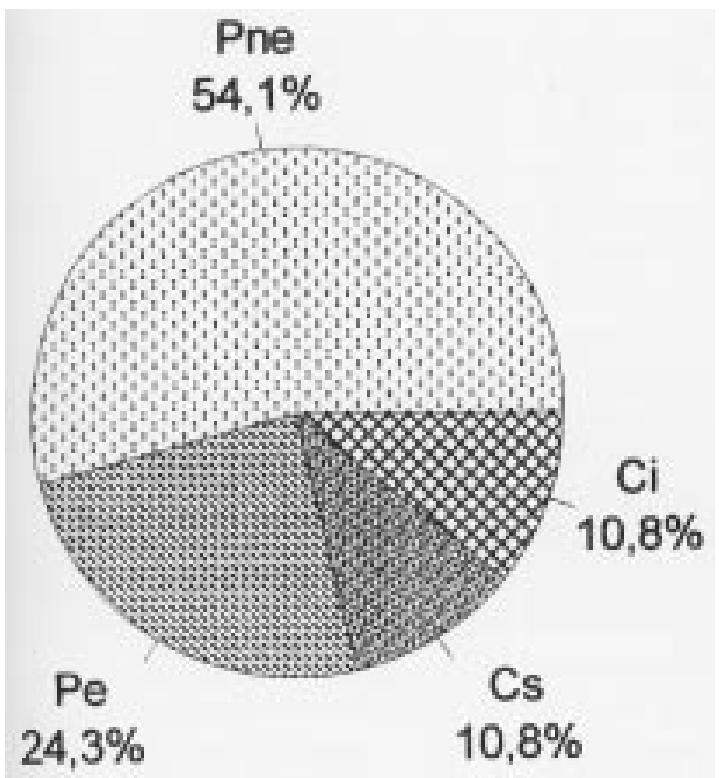

Figura 8. Proporções das espécies de mata de brejo de Itatinga, SP. Pne - peculiar não exclusiva; $\mathrm{Pe}$ - peculiar exclusiva; Cs - complementar de áreas secas; $\mathrm{Ci}$ - complementar indiferente.

periodicamente inundáveis até solos permanentemente encharcados e brejosos. Neste último caso, o guanandi muitas vezes tem vantagem seletiva sobre outras espécies e passa a ocorrer em destaque nos parâmetros quantitativos.

Em relação a Miconia ligustroides, a espécie parece apresentar alta plasticidade, já que também é citada para áreas de cerrado. Na fazenda Santa Irene, como demonstrado, ela apareceu apenas em um dos levantamentos realizados em florestas de planalto, sendo portanto incluída no grupo de peculiares não exclusivas, mas com ressalvas.

Também foram consideradas como peculiares não exclusivas, as espécies que ocorreram na floresta de brejo e nos dois levantamentos de florestas estacionais semideciduais (tabela 1). $\mathrm{O}$ fato de tais espécies apresentarem-se nos dois levantamentos realizados nas florestas de planalto diminui a probabilidade de casualidade, indicando que tais espécies ocorreriam de modo generalizado em toda a fazenda Santa Irene. O motivo pelo qual estas espécies foram incluídas no grupo de peculiares não exclusivas, foi o fato de tais espécies se apresentarem em destaque apenas na estrutura da comunidade da floresta de brejo e não nas florestas de planalto, indicando, assim, uma preferência por áreas brejosas. Nesta situação teríamos: Protium almecega, Pera obovata, Hyeronima alchorneoides, Syagrus romanzoffiana, Prunus selowii e Clethra scabra.

Como espécies complementares de áreas secas teríamos: Dendropanax cuneatum, Gochnatia polymorpha, Rapanea umbellata e Faramea cyanea (tabela 1).

Em relação a Dendropanax cuneatum, esta espécie é definida por Torres et al. (1992) como peculiar de floresta de brejo, ocupando a $9^{a}$ - posição em IVC na floresta de brejo da região de Campinas (Torres et al.1994). Na região de Itatinga, como demonstrado neste trabalho, esta espécie não se apresenta em destaque em áreas brejosas. O que se observa é que Dendropanax cuneatum é típica de baixadas mais úmidas, o que a levou a uma posição de destaque em Ml, já que esta área é coberta por floresta de planalto situada numa de bacia de sedimentação. Portanto, para melhor caracterização desta espécie, seriam necessários maiores dados sobre a sua auto-ecologia, o que possibilitaria melhor definição em relação ao seu ambiente preferencial.

No grupo de espécies complementares indiferentes foram incluídas Tapirira guianensis, Copaifera langsdorffii, Casearia decandra e Myrcia rostrata, que não apresentaram preferência por nenhum habitat, ora destacando-se em áreas brejosas, ora destacandose em áreas secas (tabela 1).

No trabalho de Torres et al. (1992), Tapirira guianensis ocupou a 1 - posição em IVC, sendo que os autores destacam ainda que esta espécie ocorreu também em Mogi-Guaçu (Gibbs et al. 1980), Porto Ferreira (Bertoni 1984), São Paulo (Struffaldi-de Vuono 1985), Campinas (Matthes et al. 1988) e Cumbica (Gandolfi 1991), geralmente com baixos valores quantitativos. De fato, em Mogi-Guaçu Tapirira guianensis ocupou a 24- posição em IVI, em São Paulo a 35- posição e em Campinas a 134a posição. Apenas em Cumbica, como também ressaltado por Torres et al. (1992), esta espécie se apresentou em destaque na comunidade ( $2^{\text {a }}$ posição em IVI), ocorrendo preferencialmente nas baixadas mais úmidas.

Tais dados possivelmente levaram Torres et al. (1994) a considerar esta espécie como peculiar de áreas de brejo. Só que isso não se confirmou neste 
trabalho, já que Tapirira guianensis ocupou a 13a posição em IVC na floresta de planície, a 3a posição na floresta de encosta e a 9a - posição na floresta de brejo, em cada área com valores próximos de densidade e freqüência, indicando uma distribuição por toda a área da fazenda.

Já em Porto Ferreira (Bertoni 1984), das quatro áreas amostradas, uma foi definida como área de várzea. Nesta, Tapirira guianensis ocupou a 38 posição das árvores com diâmetro < que $10 \mathrm{~cm} \mathrm{e}$ não foi amostrada entre as árvores de diâmetro ô a $10 \mathrm{~cm}$. Em duas das outras três áreas, a espécie ocupou a 4- e a 26- posição entre as árvores com diâmetro < que $10 \mathrm{~cm}$, não tendo sido amostrada na terceira área. Entre as árvores amostradas com diâmetro ô a $10 \mathrm{~cm}$, ela apareceu apenas em uma área, mas já ocupando a 10 10 posição. Assim, em Porto Ferreira, esta espécie apareceu em destaque na regeneração da área de várzea e como uma das principais entre as árvores componentes do estrato arbóreo de uma das áreas secas.

Portanto, tais dados nos levam a incluir Tapirira guianensis como uma espécie pertencente ao grupo de complementares indiferentes.

Ainda em relação às espécies encontradas na floresta de brejo de Itatinga, é interessante destacar a presença daquelas comumente encontradas em locais de altitudes elevadas, como Clethra scabra, Ilex paraguariensis e Podocarpus sellowii. Segundo Hueck (1972) nas altitudes mais baixas, como é o caso da área de estudo com $570 \mathrm{~m}$ de altitude, a maior quantidade de água no solo deve compensar a maior concentração de umidade do ar das grandes altitudes, podendo ser um dos fatores relacionados com a presença dessas espécies nessas áreas, mas certamente correlacionado com a temperatura, já que a área tem médias anuais baixas como em locais de maior altitude.

Para verificar a existência ou não de similaridade florística entre florestas de brejo, foram feitas comparações entre as espécies de floresta de brejo registradas neste trabalho e os resultados obtidos por Torres et al. (1994) em trecho de floresta de brejo em Campinas, SP.

No nível de espécies, o índice de Jaccard obtido foi de apenas $12,5 \%$, indicando dessemelhança florística entre as duas florestas. Apenas oito espécies são comuns aos dois levantamentos: Tapirira guianensis, Callophyllum brasiliense,
Talauma ovata, Styrax pohlii, Protium almecega (no trabalho de Torres (1994) existe P. heptaphyllum, mas acredita-se que esta seja a mesma espécie de Protium encontrada neste trabalho, ou seja $P$. almecega, que é típica de matas de brejo), Dendropanax cuneatum, Cecropia pachystachya e Prunus selowii. Em relação às famílias a similaridade é maior, chegando a $88,89 \%$. Esperava-se que, em função da restrição ambiental semelhante, essas áreas tivessem maior similaridade florística. Isto não ocorreu, provavelmente devido à condição de fragmentação natural dessa formação, já que sua presença está condicionada aos solos hidromórficos, de ocorrência restrita e descontínua no Estado, somada à forte influência das formações adjacentes na florística das florestas de brejo.

A dessemelhança florística verificada entre as florestas de brejo deste trabalho e de Torres et al. (1994) pode ser atribuída às diferenças florísticas existentes entre as florestas mesófilas semidecíduas da região de Campinas e as de Itatinga, que estariam definindo as diferenças confirmadas entre aquelas duas formações brejosas. Esta afirmação foi reforçada com a utilização do índice de Jaccard na comparação entre o trabalho executado por Matthes (1980) em floresta estacional semidecidual de Campinas, e os realizados nas florestas da mesma unidade fitogeográfica na fazenda Santa Irene (Ivanauskas et al. 1995, Nave et al. 1993). O índice de Jaccard obtido foi de apenas 12,22\% em relação à floresta de planície e 19,23\% em relação à floresta de encosta.

As diferenças florísticas existentes entre as duas áreas de floresta de brejo comparadas, resultam em diferentes espécies ocupando lugar de destaque na estrutura dessas comunidades. No trabalho de Torres et al. (1994) destacaram-se, entre as dez primeiras em IVC, as espécies Tapirira guianensis, Calophyllum brasiliense, Cedrela odorata, Talauma ovata, Styrax pohlii, Citronella gongonha, Protium almecega, Rapanea lineata, Dendropanax cuneatum e Cecropia pachystachya. Neste trabalho destacaram-se Calophyllum brasiliense, Protium almecega, Pera obovata, Podocarpus sellowii, Hyeronima alchorneoides, Copaifera langsdorffii, Rapanea guianensis, Tapirira guianensis, Miconia ligustroides e Pera obovata. Portanto, apenas as espécies Calophyllum brasiliense, Protium almecega e Tapirira guianensis ocorreram em 
destaque nos dois trabalhos, evidenciando a importância das mesmas como espécies indicadoras deste tipo de formação. O curioso é que este conjunto de espécies é constituído por duas peculiares não exclusivas de floresta de brejo (Calophyllum brasiliense e Protium almecega) e outra complementar indiferente ao fator encharcamento do solo (Tapirira guianensis).

Segundo Marques (1994), a dominância de uma espécie em uma determinada área, pode muitas vezes ser indicadora de um tipo vegetacional. Em síntese, as espécies peculiares não exclusivas e complementares indiferentes ao fator encharcamento do solo seriam as que realmente definiram a estrutura dessas florestas de brejo, já que tais espécies apresentaram uma vantagem seletiva sobre as espécies dos demais grupos (peculiares exclusivas e complementares de áreas secas) e passaram a ocupar lugar de destaque no IVC. No entanto, a composiçao florística própria dessas formações brejosas foi dada pela presença das espécies peculiares exclusivas.

Neste trabalho, dez espécies perfazem cerca de $75 \%$ do VC (Valor de Cobertura) total e, no de Torres et. al (1994) o mesmo número de espécies perfaz $93,82 \%$ do VC total. O destaque de poucas espécies e poucas famílias no VC poderia levar à conclusão errônea de que a área apresentava-se bastante perturbada, com baixa diversidade e dominância de poucas espécies, como é comum em áreas de florestas de planalto que sofreram algum tipo de perturbação antrópica. Só que, no caso das florestas de brejo, o fato é absolutamente esperado devido à condição natural de encharcamento do solo atuando como agente seletivo e restritivo de espécies. Apenas aquelas que dispõem de mecanismos morfofisiológicos para tolerar o período de alagamento conseguem instalar-se e desenvolver-se satisfatoriamente (Silva et al. 1992). Dessa forma, nas florestas de brejo, a baixa diversidade e a dominância de poucas espécies na estrutura da comunidade é determinada por um fator ambiental (encharcamento do solo) e não antrópico, o que torna muito complexa a discussão dos processos sucessionais nessa formação.

Segundo Leitão-Filho (1982) Annonaceae, Guttiferae, Euphorbiaceae e Magnoliaceae seriam famílias características das florestas de brejo do estado de São Paulo, mas estas observações foram confirmadas apenas parcialmente nos dois trabalhos realizados nessa formação.

A família Annonaceae não foi encontrada nem neste levantamento e nem no executado por Torres et al. (1994). Já Guttiferae (Clusiaceae, neste trabalho), obteve posição de destaque nos dois trabalhos (1ª posição neste e 2a no de Campinas), devido exclusivamente a Callophyllum brasiliense. Euphorbiaceae encontrou-se neste trabalho entre as três famílias de maior IVC e no trabalho de Torres et al. (1994) ocupou a 19á posição. Magnoliaceae ocupou a 4- posição no trabalho de Torres et al. (1994) e neste trabalho ocupou a $18^{\text {a }}$ posição.

Como famílias comuns dos dois trabalhos e entre as dez de maior IVC em ambos estão Anacardiaceae, Clusiaceae, Styracaceae, Burseraceae e Myrsinaceae. Estas famílias seriam então aquelas consideradas como famílias típicas das florestas de brejo no estado de São Paulo.

A família Icacinaceae aparece entre as dez de maior IVC no trabalho de Torres et al. (1994) e não foi amostrada neste trabalho e Podocarpaceae, Caesalpiniaceae e Arecaceae estão entre as dez de maior IVC neste trabalho e não foram amostradas naquele.

Estes resultados evidenciam a carência de outros levantamentos em florestas higrófilas no estado, visando uma melhor caracterização florística dessa unidade fitogeográfica que permitisse uma definição das famílias mais importantes dentro desse ecossistema, das espécies típicas, e dos seus fatores ambientais condicionantes.

Segundo Whittaker (1972), ambientes com condições extremas, como é o caso do alagamento, tem uma tendência a diminuir a diversidade de espécies. Segundo Leitão-Filho (1982), florestas de brejo apresentam baixa diversidade. Os resultados obtidos neste trabalho e no de Torres et al. (1994) confirmam estas observações, já que o índice de diversidade de Shannon (H') foi de 2,75 nats/indivíduos neste trabalho e de 2,45 nats/indivíduos no de Torres et al. (1994).

Um caráter importante desta formação seria a ocorrência de famílias representadas por uma única espécie: $78,57 \%$ neste trabalho e $69,57 \%$ no trabalho de Torres et al. (1994). São valores elevados quando comparados aos encontrados nas florestas de planalto, como por exemplo o valor de $50 \%$ 
encontrado na M1 e 62,22\% na M2 (Nave et al. 1993, Ivanauskas et al., 1995). Estes fatos novamente reforçam a seletividade de espécies características de floresta de brejo, o que mostra a especificidade destas espécies a este tipo de ambiente.

Podemos concluir que a composição florística das florestas de brejo seria definida em parte por espécies provenientes desta formação (peculiares) e em parte por espécies vindas de formações adjacentes (complementares). Comum a ambos os grupos seria o fato destas espécies apresentarem algumas formas de adaptação ecofisiológica para sobreviverem em solos sujeitos à elevada saturação hídrica, mas com eficiência distinta, que se refletem em termos estruturais. Devido à restrição ambiental, ocorre uma predominância de poucas famílias representadas em sua maioria por uma única espécie que ocorre em número elevado de indivíduos.

A análise sucessional em áreas com fortes restrições ambientais, como é o caso das florestas de brejo, é algo bastante complexo e de difícil análise e entendimento. Segundo Marques (1994), em locais como as florestas de brejo, onde o fator abiótico determinante é a água, as diferenças nas características sucessionais das espécies arbóreas são tênues, o que faz com que ocorram em um gradiente muito contínuo de situações, indo desde locais em início de sucessão secundária, até florestas mais estruturadas ou clímax, mas com diferenças florísticas e estruturais não muito claras.

Dessa forma, as espécies típicas dessas formações, adaptadas às condições de encharcamento quase permanente do solo, podem ser definidas como espécies finais de sucessão das florestas de brejo, considerando que a definição sucessional das espécies dessa unidade fitogeográfica deveria ser feita baseada também nas características adaptativas das espécies aos fatores ambientais definidores dessa formação e não apenas nas características normalmente usadas na classificação sucessionais das espécies, como velocidade de crescimento, fotoblastia, densidade de madeira, etc. O que ressaltamos é que a condição climática das florestas de brejo é definida por um conjunto de espécies típicas, que pelas características ecofisiológicas devem ser classificadas como finais da sucessão dessa unidade fitogeográfica, mesmo que apresentem características de espécies iniciais de sucessão como crescimento rápido, baixa densidade da madeira e alto forquilhamento por exemplo, que são características comuns de algumas espécies peculiares das florestas de brejo do estado. Isto porque estas espécies já sofreram uma seleção natural, sobrevivendo à condição de encharcamento do solo nas várias fases de desenvolvimento.

Portanto, a avaliação do estágio sucessional em áreas sujeitas a restrições ambientais, como o encharcamento do solo, necessita de estudos mais aprofundados, que envolvam a auto-ecologia das espécies e outros aspectos da dinâmica dessas formações, como as adaptações resultantes da fragmentação natural. Isso permitirá uma melhor definição de sua composição florística e estrutural e de quais foram as alterações resultantes da intervenção antrópica histórica nessa unidade fitogeográfica, como a eliminação das formações naturais adjacentes e alterações na dinâmica da água local e regional.

Agradecimentos - Este trabalho é parte dos resultados obtidos dentro do projeto de colaboração científica realizado entre a EUCATEX Ltda e o Depto de Botânica da ESALQ/USP, que vigorou pelo período de 01/01/93 a 31/08/94, sob título "Caracterização de remanescentes de formações florestais naturais das propriedades agrícolas da EUCATEX FLORESTAL Ltda". Os autores agradecem à EUCATEX FLORESTAL Ltda, na pessoa do Eng. Ftal. Horácio de Figueredo Luz, pelo apoio logístico e pela colaboração durante toda a realização do projeto e aos taxonomistas Osny T. Aguiar (Instituto Florestal), João Batista Baitelo (Instituto Florestal) e Inês Cordeiro (Instituto de Botânica) pelo auxílio na identificação de material botânico.

\section{Referências bibliográficas}

ACIESP. 1987. Glossário de Ecologia. ACIESP. São Paulo.

BERTONI, J.E. 1984. Composição florística e estrutura fitossociológica de uma floresta no interior do Estado de São Paulo: Reserva Estadual de Porto Ferreira. Dissertação de mestrado, Universidade Estadual de Campinas, Campinas.

BERTONI, J. E. \& MARTINS, F.R. 1987. Composição florística de uma floresta ripária na Reserva Estadual de Porto Ferreira, SP. Acta Bot. Bras. 1:17-26.

BEZERRA DOS SANTOS, L. 1975. Floresta Galeria. In Tipos e aspectos do Brasil. Fundação IBGE, Rio de Janeiro.

CAMPOS, L.F.G. 1912. Mapa Florestal. SEMA, São Paulo.

CATHARINO, E.L.M. 1989. Estudos fisionômicos florísticos e fitossociológicos em matas residuais secundárias do município de Piracicaba, SP. Dissertação de mestrado, Universidade Estadual de Campinas, Campinas.

FERNANDES, A. \& BEZERRA, P. 1990. Estudo fitogeográfico do Brasil. Stylus Comunicações, Fortaleza.

GANDOLFI, S. 1991. Estudo florístico e fitossociológico de uma floresta residual na área do Aeroporto Internacional de São Paulo, município de Guarulhos, SP. Dissertação de mestrado, Universidade Estadual de Campinas, Campinas. 
GIBBS, P.E., LEITÃO FILHO, H.F. \& ABBOT, R.J. 1980. Aplication of the point-centered quarter method in a floristic survey of an area of gallery forest at MogiGuaçu, SP, Brasil. Revta brasil. Bot. 3:17-22.

GOODLAND, R.1975. Glossário de ecologia brasileira. INPA, Manaus.

HUECK, K.1972. As florestas da América do Sul. Editora da Universidade de Brasília/Polígono, São Paulo.

IVANAUSKAS, N.M., RODRIGUES R.R. \& NAVE, A.G. 1995. Florística e fitossociologia de uma mata mesófila semidecídua localizada em Itatinga-SP. In Resumos do X Congresso da Sociedade brasileira de botânica, SBB/ FFCLRP, Ribeirão Preto, p.110.

JOLY, A.B. 1970. Conheça a vegetação brasileira. EDUSP/ Polígono, São Paulo.

JOLY, C.A. 1982. Flooding tolerance mechanisms of some brazilian trees. PhD thesis. University of St. Andrews, Saint Andrews.

JOLY, C.A. \& SILVA, S.M. 1988. Variação da composição florística de uma mata ciliar ao longo de um gradiente de declividade. In Relatório de atividades dos cursos de Ecologia de Campo I e IV. Estação Experimental de Assis do Instituto Florestal de São Paulo (H.F. LeitãoFilho, F.R. Martins, C.A. Joly, F.A.M. Santos e R.R. Rodrigues, Coords.). Assis, p.51-62.

JOLY, C.A., LIEBERG, S.A. \& SPIGOLON, J.R. 1988. Recuperação das matas ciliares do rio Jacaré-Pepira (Brotas, SP) com base no estudo fitossociológico de relictos desta formação. In Resumos do XXXIX Congresso nacional de botânica. SBB, Belém, p.423.

KOZLOWSKI, T.T. 1984. Responses of wood plants to flooding. In Flooding and plant growth (T.T. Kozlowski, Coord.). Academic Press, London, p.129-163.

LEITÃO-FILHO, H.F. 1982. Aspectos taxonômicos das florestas do Estado de São Paulo. Silvicultura em São Paulo. 1:197-206.

LIEBERG, S.A. 1990. Tolerância à inundação e aspectos demográficos de Inga affinis DC. Dissertação de mestrado, Universidade Estadual de Campinas, Campinas.

LINDMAN, C.A.M. 1906. A vegetação do Rio Grande do Sul (Brasil-Austral.). Tipografia da Livraria Universal de Echenique Irmãos \& Cia, Porto Alegre.

LINDMAN, C.A.M. \& FERRY, M.G.1974. A vegetação do Rio Grande do Sul. São Paulo, EDUSP/Livraria Itatiaia Editora, Belo Horizonte.

MANTOVANI, W. 1989. Conceituação e fatores condicionantes. In Anais do I Simpósio sobre mata ciliar (L.M. Barbosa, Coord.). Fundação Cargill, Campinas, p.11-19.

MARQUES, M.C.M. 1990. Aspectos ecofisiológicos de tolerância à inundação em Cedrella fissilis Vell. Monografia de conclusão do curso em Ciências Biológicas. Universidade Estadual de Londrina, Londrina.

MARQUES, M.C.M. 1994. Estudos auto-ecológicos do guanandi (Calophyllum brasiliense Camb. Clusiaceae) em uma mata ciliar do município de Brotas, SP. Dissertação de mestrado, Universidade Estadual de Campinas, Campinas.

MARTINS, F.R. 1993. Estrutura de uma floresta mesófila. Ed. Universidade Estadual de Campinas, Campinas.

MATTHES, L.A.F, 1980. Composição florística, estrutura e fenologia de uma floresta residual no planalto paulista: Bosque dos Jequitibás (Campinas, SP). Dissertação de mestrado, Universidade Estadual de Campinas, Campinas.

MATTHES, L.A.F.; LEITÃO-FILHO, H.F. \& MARTINS, F.R 1988. Composição florística e estrutura fitossociológica do estrato arbóreo, Bosque dos Jequitibás, Campinas. In Anais do V Congresso da Sociedade botânica de São Paulo. UNESP, São Paulo, p.55-76.
MEDRI, M.E. \& CORREA, M.A. 1985. Aspectos histológicos e bioquímicos de Joannesia princeps e Spatodea campanulata crescendo em solos na capacidade de campo, encharcado e alagado. Semina 6:147-154.

MUELLER-DOMBOIS, D. \& ELLENBERG, H. 1974. Aims and methods of vegetation ecology. Wiley, New York.

NAVE, A.G., RODRIGUES, R.R. \& IVANAUSKAS, N.M. 1993. Levantamento florístico e fitossociológico de uma mata mesófila semidecídua localizada em Itatinga-SP. In Anais da III Reunião paulista de iniciação científica em ciências agrárias e VII Congresso de iniciação científica da ESALQ. Piracicaba, p.22.

PONNAMPERUMA, F.N. 1984. Effects of flooding on soil In Flooding and plant growthed (T.T. Kozlowski, Coord.). Academic Press, London, p.10-45.

RODRIGUES, R.R. 1989. Análise estrutural de formações florestais ripárias. In Anais do I Simpósio sobre mata ciliar (L.M. Barbosa, Coord.). Fundação Cargill, Campinas, p.99-119.

RODRIGUES, R.R. 1992. Análise de um remanescente de vegetação natural às margens do rio Passa Cinco, Ipeúna, SP. Tese de doutorado, Universidade Estadual de Campinas, Campinas.

SAMPAIO, A.J. 1938. Fitogeografia do Brasil. Ed. Nacional, São Paulo.

SENA GOMES, A.R. \& KOSLOWSKI, T.T. 1988. Physiological and growth responses of Hevea brasiliensis. Biotropica 20:286-293.

SILVA, S.M., SILVA, F.C., VIEIRA, A.O.S., NAKAJIMA, J.N., PIMENTA, J.A. \& COLLI, S. 1992. Composição florística e fitossociologia do componente arbóreo das florestas ciliares da bacia do rio Tibagi, Paraná: 2. várzea do rio Bitumirim, município de Ipiranga, PR. Revista do Instituto Florestal 4:192-198.

STRUFFALDI-DE VUONO, Y. 1985. Fitossociologia do estrato arbóreo da floresta da Reserva Biológica do Instituto de Botânica (São Paulo, SP). Tese de doutorado, Universidade de São Paulo, São Paulo.

TONIATO, M.T.Z. \& LEITÃO-FILHO, H.F. 1995. Contribuição ao estudo de matas higrófilas. In Resumos do XLVI Congresso Nacional de Botânica. SBB/FFCLRP, Ribeirão Preto, p.105.

TORRES, R.B., MATTHES, L.A.F., \& RODRIGUES, R.R. 1994. Florística e estrutura do componente arbóreo de uma mata de brejo em Campinas, SP. Revta. brasil. Bot. 17:189-194.

TORRES, R.B., MATTHES, L.A.F., RODRIGUES R.R. \& LEITÃO-FILHO, H.F. 1992. Espécies florestais nativas para plantio em áreas de brejo. O Agronômico 44:13-16.

TROPPMAIR, H. \& MACHADO, M.L.A. 1974. Variação da estrutura da mata galeria na bacia do rio Corumbataí (SP) em relação à água do solo, ao tipo de margem e ao traçado do rio. Biogeografia 8:1-28.

VELOSO, H.P. 1972. Aspectos fito-ecológicos da bacia do alto rio Paraguai. Biogeografia 7:1-31.

VELOSO, H.P. \& GOES FILHO, L. 1982. Fitogeografia brasileira-classificação fisionômica-ecológica da vegetação neotropical. Bol. Técn. Radam-Brasil (série vegetação) 1:1-80.

WHITTAKER, R.H. 1972. Evolution and measurement of species diversity. Taxon 21:213-251. 